\title{
Pathways of disadvantage and smoking careers: evidence and policy implications
}

\author{
Hilary Graham, Hazel M Inskip, Brian Francis, Juliet Harman
}

J Epidemiol Community Health 2006;60(Suppl II):ii7-ii12. doi: 10.1136/jech.2005.045583

See end of article for authors' affiliations .....................

Correspondence to: Professor H Graham, University of York, Area 2, Seebohm Rowntree Building, York YO30 6AS UK; hmg501@york.ac.uk

Accepted for publication 10 June 2006

\begin{abstract}
Objectives: To investigate in older industrialised societies (a) how social disadvantage contributes to smoking risk among women (b) the role of social and economic policies in reducing disadvantage and moderating wider inequalities in life chances and living standards.

Methods: Review and analysis of (a) the effects of disadvantage in childhood and into adulthood on women's smoking status in early adulthood (b) policy impacts on the social exposures associated with high smoking risk.

Main results: (a) Smoking status-ever smoking, current smoking, heavy smoking, and cessation-is influenced not only by current circumstances but by longer term biographies of disadvantage (b) social and economic policies shape key social predictors of women's smoking status, including childhood circumstances, educational levels and adult circumstances, and moderate inequalities in the distribution of these dimensions of life chances and living standards. Together, the two sets of findings argue for a policy toolkit that acts on the distal determinants of smoking, with interventions targeting the conditions in which future and current smokers live.

Conclusions: An approach to tobacco control is advocated that combines changing smoking habits with reducing inequalities in the social trajectories in which they are embedded. Policies to level up opportunities and living standards across the lifecourse should be championed as part of an equity oriented approach to reducing the disease burden of cigarette smoking.
\end{abstract}

d older industrialised societies where smoking related diseases are the major cause of morbidity and premature mortality, tobacco control is the cornerstone of public health policy. ${ }^{1}$ Since the 1970 s, tobacco use has been increasingly regulated, with restrictions on cigarette packaging, price, advertising and promotion, sales outlets, and smoking in public places, and treatment services have been expanded. ${ }^{2}{ }^{3}$ While broad ranging, these measures rely on a common mechanism through which to achieve their effect. The different components of tobacco control policy seek to change smoking habits directly, by controlling the promotion, purchase, and consumption of cigarettes.

The sharp fall in smoking prevalence in older industrialised societies has been attributed to the success of this approach. ${ }^{3-5}$ However, rates have not fallen uniformly across the population. The decline is less pronounced in early adulthood, ${ }^{6}$ among those in disadvantaged circumstances, and for women. ${ }^{7-11}$ In consequence, young adult women in disadvantaged circumstances make up an increasing proportion of the shrinking population of smokers.

The paper focuses on this subgroup of smokers. It does so to examine the case for tobacco control policies that target not only smoking habits but the structures of disadvantage in which they are embedded. We investigate how disadvantaged pathways shape women's smoking status in early adulthood, before turning to evidence on how social policies can reduce inequalities in life chances and living standards, not only for women, but for the whole population.

\section{DISADVANTAGED PATHWAYS AND SMOKING CAREERS: EVIDENCE}

Historical evidence makes clear that the commercial production and marketing of cigarettes underlies the smoking epidemic that first hit older industrialised societies and has subsequently spread worldwide. ${ }^{12-14}$ In Europe and the USA for example, pipes, cigars, snuff, and chewing tobacco were the dominant forms of tobacco use until the late 19th century, and levels of consumption, particularly among women, were low. ${ }^{15}{ }^{16}$ In the early decades of the 20th century, traditional products were displaced by manufactured cigarettes, a milder and more addictive mode of tobacco consumption. ${ }^{17}$ In a pattern now being repeated on a global scale, the new tobacco product was first taken up by higher socioeconomic groups. ${ }^{10} 14$ The smoking of manufactured cigarettes became part of an urban lifestyle that embodied sophistication. ${ }^{17}{ }^{18}$ But as the habit became more widely adopted, its symbolic value declined and the socioeconomic profile of smoking changed. ${ }^{15} 1619$

Trends in the UK, where national surveys have been tracking rates of tobacco use by social class since the 1940s, provide an example. By the 1940s-and well before the health risks of smoking were exposed by researchers and were made public through health promotion campaigns - the prevalence of cigarette smoking among men and women in higher socioeconomic groups was already declining. ${ }^{16}$ Rates of cigarette smoking in poorer groups continued to rise until the 1960s (men) and 1970s (women). ${ }^{6}{ }^{16}$ As in other societies where smoking rates have peaked, smoking among both women and men is increasingly a signifier of disadvantage.

Thus among women, poor childhood circumstances, as measured by parental occupation/education, is associated with higher rates of regular smoking and higher levels of cigarette consumption in adolescence. ${ }^{20} 21$ Both poor adult circumstances and heavy smoking independently reduce the odds of quitting across adulthood, ${ }^{22-24}$ and in pregnancy. ${ }^{22} 25$ Socioeconomic differentials are evident across ethnic groups, including African-American and white women in the USA, ${ }^{26}$ Maori and white women in New Zealand, ${ }^{3}$ and white women in the UK. ${ }^{27}$

Cross sectional data are the primary source of evidence on these socioeconomic differentials. However, both women's circumstances and their smoking habits are shaped 
longitudinally from childhood, through the child to adult transition, and into adulthood. Thus childhood socioeconomic circumstances have an effect on the odds of persistent smoking $^{21}$ and quitting ${ }^{28}$ in adulthood that remains after adjustment for adult socioeconomic circumstances. This effect is not explained by factors related to the cultural environment of the home, like parental education and parental smoking or by early tobacco dependence. ${ }^{21} 23$

Children's circumstances powerfully influence their educational trajectories. ${ }^{29}$ Educational trajectories (as measured by age of leaving education and educational qualifications) are associated with smoking uptake in adolescence, ${ }^{20}$ as well as with current smoking, ${ }^{30}{ }^{31}$ heavy smoking, ${ }^{32}$ and quitting in adulthood. ${ }^{24}$ Education eliminates the effect of childhood circumstances on these dimensions of smoking status, ${ }^{21}{ }^{31}$ suggesting that childhood conditions exert their influence through education.

Education in turn determines adult socioeconomic position, ${ }^{33}$ with poor adult circumstances adding further to the risk of smoking in adulthood, ${ }^{23}{ }^{30}$ and reducing the odds of quitting. ${ }^{24}$ Adolescent smoking status has been found to predict educational level and adult socioeconomic position, with smoking related social mobility contributing to the association between smoking and both educational and adult disadvantage. ${ }^{2134}$

The contribution of childhood conditions, education, and adult circumstances to adult smoking risk is also evident among men, although the effects of childhood conditions on adult smoking status are less pronounced than for women..$^{28} 35$ But research is uncovering an additional dimension to women's socioeconomic lifecourse. For women, continuities in disadvantage from childhood to adulthood are mediated by their reproductive and domestic careers, and by early parenthood in particular.

While rates of early motherhood vary between societies, it is women from poorer backgrounds who are more likely to be mothers by their early 20 s and to bring up children outside a cohabiting relationship. ${ }^{37}$ Qualitative studies suggest that early and lone motherhood are lifecourse strategies fashioned out of hardship, through which women access valued identities and supportive relationships. ${ }^{39} 40$ But, like early school leaving, they are gateways into adulthood that have adverse consequences for both future circumstances and smoking careers. Thus, early and lone motherhood is associated with long term disadvantage. ${ }^{41}{ }^{42}$ Early motherhood also increases the odds of smoking and reduces the odds of quitting, over and above the effects of childhood conditions, education, and adult socioeconomic position. ${ }^{23}{ }^{43}$ Lone motherhood also, but more modestly, increases the risk of smoking. ${ }^{23}{ }^{43}$ As a result, the children of young and single mothers are at increased risk of passive smoking: gendered trajectories of disadvantage damage the health both of women and their children.
Table 2 Effect of a disadvantaged lifecourse on the odds of being a light smoker ( $<15$ a day) and heavy smoker ( $\geqslant 15$ a day) compared with women non-smokers

\begin{tabular}{ll}
\hline & Odds ratio $(95 \% \mathrm{Cl})$ \\
\hline Current light smoker & $0.94(0.92,0.95)$ \\
Age & $1.14(1.02,1.28)$ \\
Childhood disadvantage & $1.71(1.52,1.93)$ \\
Left school $\leqslant 16$ & $1.34(1.15,1.56)$ \\
Age of motherhood $<22$ & $1.96(1.69,2.28)$ \\
Adult disadvantage & $0.99(0.97,1.01)$ \\
Current heavy smoker & $1.40(1.24,1.59)$ \\
Age & $2.31(2.02,2.65)$ \\
Childhood disadvantage & $1.95(1.67,2.27)$ \\
Left school $\leqslant 16$ & $2.21(1.90,2.57)$ \\
Age of motherhood $<22$ & \\
Adult disadvantage & \\
\hline
\end{tabular}

A British survey of women provides illustrative evidence of the links between lifecourse disadvantage and smoking status. $^{44}$ It relies on self reported smoking status that validation studies show are broadly reliable, ${ }^{45}$ with no systematic socioeconomic bias in underreporting. ${ }^{46}$ Located in southern England and representative of its study population, most of the survey participants are white (94\%). Participants were interviewed between 1998 and 2002, and we focus on those aged $22-34$ years $(n=9936)$.

Four lifecourse markers were used: childhood disadvantage (father in routine/semi-routine occupation at birth or no contact with father, $38 \%$ of the sample), educational disadvantage (leaving full time education $\leqslant 16$ years, the minimum school leaving age, $41 \%$ ), early motherhood (by 22 years, $18 \%$ ), and severe adult disadvantage (reliance on means tested welfare benefits, 18\%). In the UK, these benefits provide an income appreciably below the EU poverty line. ${ }^{47}$

Table 1 describes the overall rates of ever having smoked $(\geqslant 1$ cigarette/day for $\geqslant 1$ year $)$, current smoking $(\geqslant 1$ cigarette/day), heavy smoking (current smoker $\geqslant 15$ cigarette/day), and former smoking (ever smokers not currently smoking). It then maps the association between disadvantaged trajectories and these dimensions of smoking status. Cumulative exposure to disadvantage is associated with each dimension. Thus, among women who have experienced childhood disadvantage, educational disadvantage and early motherhood and who now live with financial hardship, 76\% were ever smokers, and $63 \%$ were current smokers. For women experiencing none of these disadvantages, the rates were respectively $33 \%$ and $18 \%$. Cumulative disadvantage is also associated with higher rates of heavy smoking (56\% compared with $35 \%$ for advantaged women) and with lower rates of former smoking ( $17 \%$ compared with $45 \%$ ).

Table 1 Disadvantaged trajectories and smoking status of women aged 22-34, England, 1998-2002

\begin{tabular}{|c|c|c|c|c|c|}
\hline & Number & $\begin{array}{l}\text { Ever } \\
\text { smoked (\%) }\end{array}$ & $\begin{array}{l}\text { Current } \\
\text { smoker (\%) }\end{array}$ & $\begin{array}{l}\text { Heavy smoker } \\
\text { (as \% of current } \\
\text { smokers) }\end{array}$ & $\begin{array}{l}\text { Former smoker } \\
\text { (as \% of ever } \\
\text { smokers) }\end{array}$ \\
\hline $\begin{array}{l}\text { Whole sample } \\
\text { Sample with: }\end{array}$ & 9936 & 45.6 & 29.8 & 45.1 & 34.6 \\
\hline childhood disadvantage & 3800 & 51.6 & 35.9 & 49.6 & 30.4 \\
\hline $\begin{array}{l}\text { plus left full time education } \\
\leqslant 16\end{array}$ & 2081 & 61.0 & 44.1 & 53.3 & 27.7 \\
\hline plus a mother $<22$ & 744 & 70.3 & 54.6 & 57.1 & 22.4 \\
\hline plus adult disadvantage & 405 & 75.6 & 62.5 & 56.1 & 17.3 \\
\hline none of these & 3614 & 33.3 & 18.3 & 34.5 & 45.1 \\
\hline
\end{tabular}




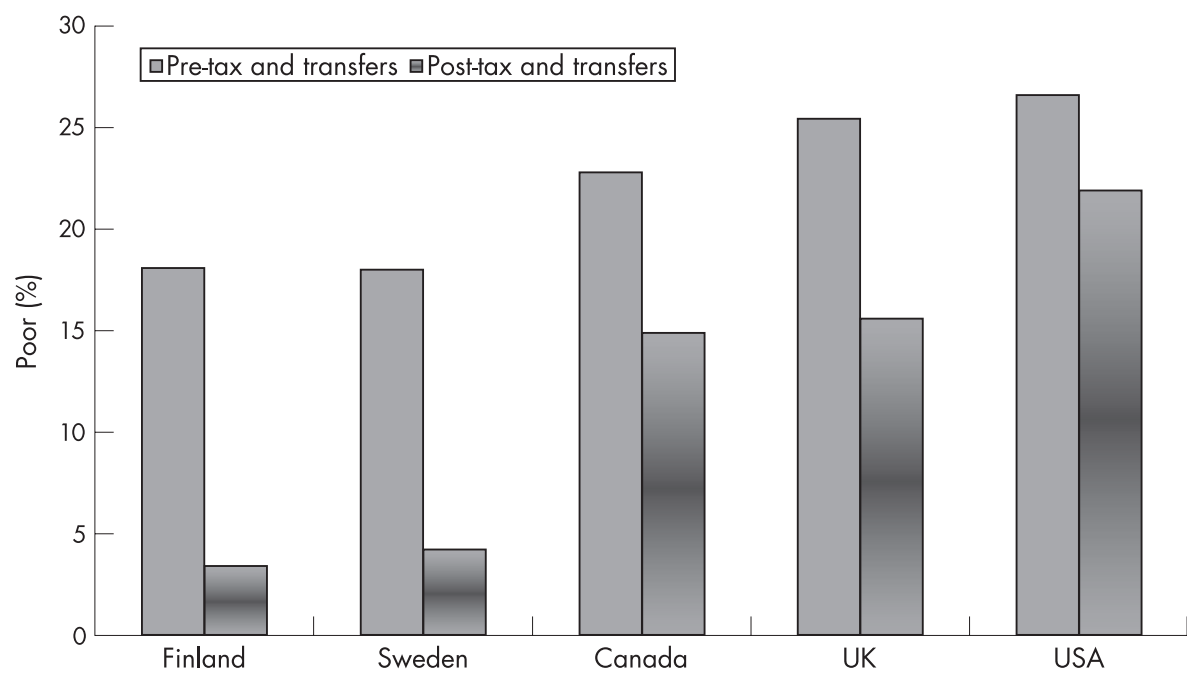

Figure 1 Percentage of children in poverty (in households below $50 \%$ of median national income before and after tax and social transfers). Source: Unicef. ${ }^{51}$

Binary logistic regression analyses confirmed that each dimension of disadvantage contributed independently to smoking risk, increasing the odds of ever smoking, current smoking, and heavy smoking and reducing the odds of former smoking (results not given). We then modelled the effect of a disadvantaged lifecourse on these dimensions of smoking status using multinomial logistic regression, entering lifecourse factors in their temporal sequence (childhood disadvantage before leaving school $\leqslant 16$, etc). Taking nonsmokers as the reference group, table 2 shows the effects of each dimension of disadvantage on the odds of being a light smoker $(<15$ cigarettes/day) and heavy smoker $(\geqslant 15$ cigarettes/day) in the fully adjusted model. A value $>1$ shows that the dimension increases the odds of being a light/ heavy smoker compared with the odds of being a nonsmoker. Thus, compared with non-smokers, leaving full time education at the minimum leaving age increased the odds of light smoking by a factor of 1.71 and of heavy smoking by 2.31. Becoming a mother before 22 years further increased the odds of these outcomes, by 1.34 and 1.95 respectively.

Confirming patterns found in other studies, table 2 illustrates how women's smoking careers develop, and are sustained, along disadvantaged trajectories. While evident for light smokers, the long term and cumulative effects of disadvantage are more pronounced for women smoking more than 15 cigarettes a day.

\section{DISADVANTAGED PATHWAYS AND SMOKING CAREERS: POLICY IMPLICATIONS}

Evidence linking women's smoking habits to pathways of disadvantage can help guide tobacco control policies not only for women but for the population as a whole. These policies currently focus on the proximal determinants of smoking: on improving knowledge of tobacco's harmful effects, increasing motivation and self efficacy and, through pharmacological therapies, reducing nicotine dependence. While evaluations and meta reviews suggest that these interventions can be effective, there are reasons to doubt whether, on their own, they can break the link between lifecourse disadvantage and cigarette smoking.

Firstly, increasing investment in interventions to tackle the proximal determinants of smoking uptake and persistence has coincided with widening socioeconomic differentials in smoking status in older industrialised societies. ${ }^{16}{ }^{19}$ It is a trend that conforms to Victora et al's "inverse equity hypothesis", in which higher socioeconomic groups are better placed to access, utilise, and derive health benefits from effective interventions than poorer groups. ${ }^{48}$ Secondly, lower entry rates into, and higher exit rates from, smoking among advantaged groups is leaving behind a smoking population that is increasingly disadvantaged and nicotine dependent. It should therefore be anticipated that interventions successful in earlier decades may fail to achieve the same results for current and future generations of smokers. Thirdly, in a number of high income societies, including the UK and the USA, inequalities in key predictors of cigarette smoking have widened. For example, the proportion of children living in relative poverty has risen sharply in both countries since the $1970 \mathrm{~s}^{49}$; at the same time, the influence of family background on educational attainment, and of attainment on occupation, has increased..$^{29}$ Inequalities in living standards in adulthood have also widened..$^{50}$ The relative position of disadvantaged smokers has therefore worsened, a trend likely to make it more difficult for interventions to reduce smoking rates in poorer groups.

The link between social disadvantage and smoking status argues for a new approach to reducing smoking prevalence. Specifically, it argues for a concept of tobacco control that looks beyond changing smoking behaviour to moderating the social conditions that shape it. This broader concept shifts the focus from individual level interventions to societal level policies.

Measuring the impacts of social policies presents its own challenges. Policies are typically rolled out in ways that make them difficult to evaluate using experimental research designs; cross national comparisons, cross cohort studies, and time series data are therefore used to map their effects on the scale and distribution of disadvantage. Furthermore, gender differences in policy impacts are not routinely investigated, and smoking status is rarely included as an outcome measure. None the less, policy analyses provide a useful resource for strategies to narrow socioeconomic differential in tobacco use.

Firstly, these analyses confirm the importance of the macropolicy environment in influencing factors that predict women's smoking status, including childhood circumstances, educational opportunities, and adult socioeconomic position. Even in today's global economy, when national labour markets are increasingly constrained by the international organisation of production and trade, national policies have been found to have pronounced effects on the scale and distribution of disadvantage, in childhood and across the lifecourse..$^{47} 49$ 
Secondly, analyses help to pinpoint the mechanisms through which social policies exert their influence on people's lives. Across older industrialised societies, the effects are mediated through three important instruments of redistribution: taxation, cash benefits paid through the social security system ("social transfers"), and publicly funded services, like education, health care, and housing.

\section{Tax and social transfers}

The impact of tax and social transfer policies is captured in cross national analyses of child poverty. These measure a country's child poverty rate against the threshold of average household income (adjusted for household size and composition) in that country. In figure 1, children in households with an income below $50 \%$ of median income are defined as poor. It suggests that, across high income societies, tax and transfers reduce children's exposure to poverty. However, the effectiveness of these redistributive mechanisms varies. The contrast is sharpest between the Nordic countries (Sweden, Finland, Norway), where welfare systems are based on the inclusive provision of cash benefits pegged to average incomes, and systems that rely on means tested benefits well below average incomes (the USA and UK). In Sweden, childhood poverty rates fall by $78 \%$ (from $18 \%$ to $4 \%$ ) after tax and transfers; in the USA, rates fall by $26 \%$ (from $27 \%$ to $22 \%$ ).

Welfare reform has been vigorously pursued in the USA, where single mothers are the principal beneficiaries of transfers through the social assistance system. The major social assistance programme was replaced in 1997 with one designed to encourage single mothers into the labour market through a package of support (for example, help with job searching and vocational training). Evaluation suggests that the welfare to work programme lifted employment rates and incomes, with effects still evident six years later. ${ }^{52}$ However, while these effects suggest that women's financial circumstances improved, cross sectional studies of the smoking status of single mothers before and after welfare reform indicate that rates of current smoking were higher and quit rates were lower in the post-reform period. ${ }^{53}$ As the authors note, the financial gains of moving into paid work are likely to be offset by social costs, including poor working conditions, shiftwork, and childcare difficulties, which may work against positive changes in smoking behaviour.

Since 1997, the UK government has also pursued major welfare reform, using the tax and transfer system as policy levers through which to improve the socioeconomic circumstances of children in low income families. The changes have combined to raise employment rates among single mothers, ${ }^{54}$ reduce child poverty, ${ }^{55}$ and increase spending by poor families on resources that promote child welfare (children's clothes and shoes, fruit and vegetables, toys, books, etc). ${ }^{56}$ The improvement in family circumstances has also been associated with reduced household spending on tobacco and alcohol. ${ }^{56}$ Evidence at the level of the individual is limited. However, as in the USA, it suggests that improved financial circumstances do not, at least in the short term, result in improvements in women's smoking status. A longitudinal study with data on low income mothers targeted by the welfare programme developed a hardship scale to separate the poor from the poorest, based on debts, essential items that are unaffordable, and anxieties about money. Using this scale, it assessed the effect of improved circumstances on changes in smoking status. It found that effects depended on the degree of initial disadvantage. For single and cohabiting mothers who, at the baseline survey, had higher educational levels and experienced less severe hardship, moving out of hardship was associated with higher quit rates. But for mothers who had previously endured severe hardship,

\section{What this paper adds}

- Develops a perspective on tobacco control directed not only to smoking habits but to the structures of disadvantage in which they are embedded;

- Focusing on women, discusses evidence of how disadvantaged pathways shape smoking status in early adulthood;

- Provides examples of how policies can moderate-or amplify-structures and pathways of disadvantage

improved circumstances did not act as a trigger for cessation (unpublished data). As this suggests, past disadvantage has persisting effects on smoking careers.

\section{Publicly funded services}

This third policy instrument includes both targeted interventions for disadvantaged groups and universal services for the whole population. Educational services provide an example of both approaches.

Targeted pre-school education programmes have been found to have longlasting effects on the social trajectories of poor children, improving their educational levels and employment prospects. A widely reported case study is the High/Scope Perry Preschool project, which randomly assigned poor black children to receive an intensive pre-school programme at age 3 to 5 years. At 19 and 27 years, women enrolled in the programme had higher educational attainment, lower rates of teenage births and births outside marriage, higher rates of employment, and higher incomes than the control group. ${ }^{58}$ But while intensive interventions can help lift poor children on to more advantaged pathways, their life chances remain significantly poorer than those of advantaged children not in receipt of targeted support..$^{59}$

Publicly funded school systems have a larger part to play in breaking the link between childhood and adult disadvantage. Cross national analyses suggest that poor children fare better under some systems than others, with the strength of the relation between family background and educational attainment varying across societies. For example, the relation is weaker in Canada and the Nordic countries than in the UK and USA. ${ }^{29}$ Important changes in the UK's educational system, including the introduction of a unified system of examinations and the rapid expansion of higher (university level) education, have failed to promote greater intergenerational mobility. Instead, socioeconomic differentials in young people's examination performance at 16 and in entry rates to higher education have increased. ${ }^{29}{ }^{60}$

\section{Policy implications}

- Sheds light on why conventional approaches to tobacco control are unlikely to be sufficient to break the link between social disadvantage and cigarette smoking;

- Makes the case for a "joined up" approach to tobacco control, concerned with changing smoking behaviour and the social conditions that shape it;

- Highlights how government policies-using taxation, welfare cash benefits, and publicly funded servicesaffect the social determinants of smoking 
Publicly funded services also include those designed to reduce teenage pregnancy, through the provision of sex education and access to contraceptive services. A metaanalysis of preventive strategies concluded that they do not reduce unintended pregnancies among young women aged $11-18 .^{61}$ Qualitative studies shed light on why. They suggest that teenage pregnancy and motherhood are integral to broader strategies through which individuals and families build self affirming identities in the face of long term disadvantage, with young women who face a lifetime of hardship investing in motherhood and the social relationships that it sustains. ${ }^{3962}$ Such findings underline the case for acting directly on childhood poverty and educational inequality.

\section{CONCLUSIONS}

With cigarette smoking increasingly confined to poorer groups, the tobacco control community is being urged to identify "what messages and interventions work to get lower socioeconomic groups to stop smoking". ${ }^{63}$ To date, the policy response has been to increase investment in conventional approaches to tobacco control, extending the range and intensity of interventions acting on the individual level influences on smoking. However, it is possible that improved messages and more interventions are not enough: that the barriers lie in the social disadvantages to which recipients are exposed.

The paper has reviewed research suggesting that this is the case. By turning a spotlight on women in early adulthood, it has presented evidence that smoking status-including uptake, persistence, consumption, and cessation-is influenced by biographies of disadvantage. These biographies begin with poor circumstances in childhood, and are subsequently shaped by both educational trajectories and reproductive careers. In line with other analyses, early school leaving, early entry into motherhood and reliance on means tested benefits emerged as important predictors of current and, particularly, heavy smoking. It is important to recognise that these patterns are mapped in observational studies, with predictors like early school leaving serving as markers of more complex and dynamic processes that link lifecourse inequalities to lifestyle differences. For example, sociological studies are uncovering the dimensions of advantage associated with staying on at school and gaining qualifications. Drawing on the work of Pierre Bourdieu, ${ }^{64}$ they point to how parents from advantaged backgrounds who have themselves done well at school can provide their children with "cultural capital" (linguistic and cognitive skills, self confidence, a sense of entitlement, etc) that facilitates progress at school. ${ }^{65}{ }^{66}$ Cultural capital, in turn, is likely to reinforce any direct effects that educational success has on young people's smoking careers. As this suggests, interventions that focus on individual predictors of smoking, like early school leaving, should not be expected to have unmediated effects on smoking careers.

While the causal pathways are likely to be complex, evidence on the social predictors of women's smoking challenges the tobacco control community to "think outside the box": to focus not only smoking habits but on the social trajectories in which they are embedded. It requires a policy toolkit that acts on distal as well as proximal determinants of smoking, with interventions targeting smokers and the conditions in which they live.

As a contribution to this toolkit, we have reviewed evidence of the impact of macro-policies and targeted programmes on the distal determinants of smoking. Until measures of smoking behaviour, including nicotine dependence, are routinely incorporated into evaluations of these interventions, it will not be possible to track how changes in social conditions affect changes in smoking habits. However, our review suggests that social interventions influence the social predictors of smoking status, including childhood conditions, education opportunities, and adult circumstances. In so doing, they mediate the effects of conventional tobacco control interventions that seek to change smoking habits directly.

This suggests that social policies are tobacco control policies. It suggests that policies that level-up opportunities and living standards across the lifecourse have an important part to play in reducing socioeconomic differentials in smoking, for both women and men. They should be championed as part of an equity oriented approach to reducing the disease burden of cigarette smoking.

\section{ACKNOWLEDGEMENTS}

We thank the women who took part in the Southampton women's survey, the SWS Study Group, and the survey staff who recruited the women and collected and processed the data. Two JECH reviewers provided helpful comments that were taken into account in revising the paper.

\section{Authors' affiliations \\ H Graham, Department of Health Sciences, University of York, UK \\ H M Inskip, MRC Epidemiology Resource Centre, University of \\ Southampton, Southampton General Hospital, UK}

B Francis, J Harman, Centre for Applied Statistics, Lancaster University, UK

Funding: the paper forms part of a project based on the SWS funded by Cancer Research UK, grant no C5649/A4694. The SWS was funded by the Dunhill Medical Trust, the Medical Research Council, and the University of Southampton.

Conflicts of interest: none.

\section{REFERENCES}

1 Peto R, Lopez AD, Boreham J, et al. Mortality from smoking in developed countries 1950-2000. Oxford: Oxford University Press, 1994.

2 US Department of Health and Human Services. Reducing tobacco use: report of the surgeon general. Atlanta, GA: US Department of Health and Human Services, Centers for Disease Control and Prevention, National Center for Chronic Disease Prevention and Health Promotion, Office on Smoking and Health, 2000.

3 Hills SE, Blakely TA, Howden-Chapman P. Could mainstream anti-smoking programmes increase inequalities in tobacco use? Journal of Public Health Advance Access 2006;29:279-84.

4 Townsend J, Roderick P, Cooper J. Cigarette smoking by socioeconomic group, sex and age: effects of price, income and health publicity. BMJ 1994;309:923-7

5 Gilpin EA, Pierce JP. Demographic differences in patterns in the incidence of smoking cessation: United States 1950-1990. Ann Epidemiol 2002;12:141-50.

6 Office for National Statistics (ONS). Living in Britain: results from the 2003 general household survey. London: The Stationery Office, 2004.

7 Escobedo LG, Peddicard JP. Smoking prevalence in US birth cohorts: the influence of gender and education. Am J Public Health 1996;86:231-6.

8 US Department of Health and Human Services. Women and smoking: report of the surgeon general 2001. Atlanta, GA: US Department of Health and Human Services, Centers for Disease Control and Prevention, National Center for Chronic Disease Prevention and Health Promotion, Office on Smoking and Health, 2001.

9 Pierce JP, Fiore MC, Novotny TE, et al. Trends in cigarette smoking in the United States. Educational differences are increasing. JAMA 1989;261:56-60.

10 Graham H. Smoking prevalence among women in the European Community, 1950 to 1990. Soc Sci Med 1996;43:243-54.

11 Cavelaars $\mathbf{A E}$, Kunst $A E$, Geurts JJ, et al. Educational differences in smoking: international comparison. BMJ 2000;320:1102-7.

12 Lopez AD, Collishaw NE, Piha T. A descriptive model of the cigarette epidemic in developed countries. Tob Control 1994;3:242-7.

13 Nicolaides-Bouman A, Wald N, Forey B, et al. International smoking statistics. Oxford: Oxford University Press, 1993.

14 Jha P, Chaloupka F. Tobacco control in developing countries. Oxford: Oxford University Press, 2000.

15 Graham H. When life's a drag: women, smoking and disadvantage. London: HMSO, 1993.

16 Wald N, Nicolaides-Bouman A. UK tobacco statistics. Oxford: Oxford University Press, 1991.

17 Goodman J. Tobacco in history. London: Routledge, 1993. 
18 Hilton M. Smoking in British popular culture 1800-2000. Manchester: Manchester University Press, 2000.

19 Pierce JP. International comparisons of trends in cigarette smoking prevalence. Am J Public Health 1989;79:152-7.

20 Glendinning A, Shucksmith J, Hendry L. Social class and adolescent smoking behaviour. Soc Sci Med 1994;38:1449-60.

21 Jefferis B, Graham H, Manor O, et al. Level of cigarette consumption and socioeconomic circumstances in adolescence: how do they affect cigarette smoking? Addiction 2003;98:1765-72.

22 Ebrahim SH, Floyd RL, Merritt RK, et al. Trends in pregnancy-related smoking rates in the United States, 1987-1996. JAMA 2000;283:361-6.

23 Jefferis B, Power C, Graham H, et al. Effects of childhood socio-economic circumstances on persistent smoking. Am J Public Health 2004;94:279-85.

24 Graham H, Der G. Patterns and predictors of smoking cessation among women. Health Promot Int 1999; 14:231-9.

25 Lu Y, Tong S, Oldenburg B. Determinants of smoking and cessation during and after pregnancy. Health Promot Int 2001;16:355-65.

26 Barbeau EM, Krieger N, Soobader M-J. Working class matters: socioeconomic disadvantage, race/ethnicity, gender and smoking in NHIS 2000. Am J Public Health 2004;94:269-78.

27 Erens B, Primatesta P, Prior G, eds. Health survey for England 1999: the health of minority ethnic groups. London: The Stationery Office, 2001.

28 Power C, Graham H, Due P, et al. The contribution of childhood and adult socioeconomic position to adult obesity and smoking behaviour: an international comparison. Int J Epidemiol 2005;34:355-44.

29 Blanden J, Gregg P, Machin S. Intergenerational mobility in Europe and North America. London: Centre for Economic Performance, London School of Economics, 2005.

30 Graham H, Der G. Influences on women's smoking status: the contribution of socio-economic status in adolescence and adulthood. Eur J Public Health 1999b;9:137-41

31 Graham H, Hunt K. Socio-economic influences on women's smoking in adulthood: insights from the West of Scotland twenty-07 study. Health Bull 1998;56:51-8.

32 Graham H, Der G. Patterns and predictors of cigarette consumption among women. Health Educ Res 1999c;14:611-18.

33 Bynner J, Parsons S. Getting on with qualifications. In: Bynner J, Ferri E, Shepherd P, eds. Twenty-something in the 1990s. Aldershot: Aldgate, 1997.

34 Koivusilta L, Rimpela A, Rimpela M. Health related lifestyle in adolescence predicts adult educational level. J Epidemiol Community Health 1998;52:794-801.

35 Blane D, Hart CL, Davey Smith G, et al. Association of cardiovascular disease risk factors with socioeconomic position during childhood and during adulthood. BMJ 1996;313:1434-8

36 Brunner E, Shipley MJ, Blane D, et al. When does cardiovascular risk start? Past and present socioeconomic circumstances and risk factors in adulthood. $J$ Epidemiol Community Health 1999;53:757-64.

37 Singh S, Darroch JE, Frost JJ, et al. Socioeconomic disadvantage and adolescent women's sexual and reproductive behaviour: the case of five developed countries, Fam Plann Perspect 2001;33:251-8.

38 Ekert-Jaffé $\mathrm{O}$, Joshi $\mathrm{H}$, Lynch $\mathrm{K}$, et al. Fertility, timing of births and socioeconomic status in France and Britain. Population-E 2002;57:475-505.

39 Burton LM. Teenage childbearing as an alternative life-course strategy in multigenerational black families. Human Nature 1990;1:123-43.

40 Graham H, McDermott E. Qualitative research and the evidence-base of policy: insights from studies of teenage mothers in the UK. J Soc Policy 2006;35:1.

41 Hobcraft J, Kiernan K. Childhood poverty, early motherhood and adult social exclusion. B J Sociol 2001;52:495-517.
42 Dorsett R, Marsh A. The health trap: poverty, smoking and lone parenthood. London: Policy Studies Institute, 1998.

43 Graham H, Francis B, Inskip H, et al. Socioeconomic lifecourse influences on women's smoking status in early adulthood. J Epidemiol Community Health 2006;60:228-33.

44 Inskip HM, Godfrey KM, Robinson SM, et al. Cohort profile: the Southampton women's survey. Int J Epidemiol 2006;35:42-8.

45 Patrick DL, Cheadle A, Thompson DC, et al. The validity of self-reported smoking: a review and meta-analysis. Am J Public Health 1994;84:1086-93.

46 Vartiainen E, Seppälä T, Lillsunde $P$, et al. Validation of self reported smoking by serum cotinine measurement in a community based study. J Epidemiol Community Health 2005;56:167-70.

47 Ritakallio V-M, Bradshaw J. Family poverty in the European Union. In: Bradshaw J, Hatland A, eds. Social policy, employment and family change in comparative perspective. Cheltenham: Edward Elgar, 2006.

48 Victora CG, Vaughan JP, Barros FC, et al. Explaining trends in inequities: evidence from Brazilian child health studies. Lancet 2000;356:1093-8.

49 Ritakallio V-M. Trends in poverty and income inequality in cross-national comparison. European Journal of Social Security 2002;4:151-77.

50 Smeeding T. Globalization, inequality and the rich countries of the G-20: evidence from the Luxembourg income study (LIS). New York: Maxwell School of Citizenship and Public Affairs, Syracuse University, 2002.

51 Unicef. Child poverty in rich countries 2005. Florence: Innocenti Research Centre, 2005.

52 Greenberg D, Ashworth A, Cebulla A, et al. Do welfare-to-work programmes work for long? Fiscal Studies 2004;25:27-53.

53 Kaplan GA, Siefert K, Ranjit N, et al. The health of poor women under welfare reform. Am J Public Health 2005;95:1252-8.

54 Hills J, Waldfogel J. A 'Third Way' in welfare reform? Evidence from the UK. Journal of Policy Analysis and Management 2004;23:765-88.

55 Brewer M, Goodman A, Shaw J, et al. Poverty and inequality in Britain: 2005. London: Department for Work and Pensions, 2005.

56 Gregg P, Waldfogel J, Washbrook E. Expenditure patterns post-welfare reform in the UK: Are low-income families starting to catch up? London: Centre for Analysis of Social Exclusion, London School of Economics, 2005.

57 Reference withdrawn.

58 Schweinhart L, Barnes HV, Weikart DP. Significant benefits: the High/Scope Perry preschool study through age 27. Michigan: High/Scope Press, 1993.

59 Hertzman C, Weins M. Child development and long-term outcomes: a population health perspective and summary of successful interventions. Soc Sci Med 1996;43:1083-95.

60 Demack S, Drew D, Grimsley M. Minding the gap: ethnic, gender and social class differences in attainment at 16, 1988-95. Race Ethnicity and Education 2000;3:117-43.

61 DiCenso A, Guyatt G, Willan A, et al. Interventions to reduce unintended pregnancies among adolescents: systematic review of randomised control trials. BMJ 2002;324:1426-35.

$62 \mathrm{McD}$ ermott E, Graham H. Resilient young mothering: social inequalities, late modernity and the 'problem' of 'teenage' motherhood. Journal of Youth Studies 2005;8:59-79.

63 Wanless D. Securing good health for the whole population: population health trends. London: HMSO, 2003.

64 Bourdieu P. Distinction. Cambridge: Polity Press, 1986.

65 Reay D. Class work: mothers' involvement in children's schooling. London: University College Press, 1998.

66 Reay D. Education and cultural capital: the implications of changing trends in education policies. Cultural Trends 2004;13:73-86. 